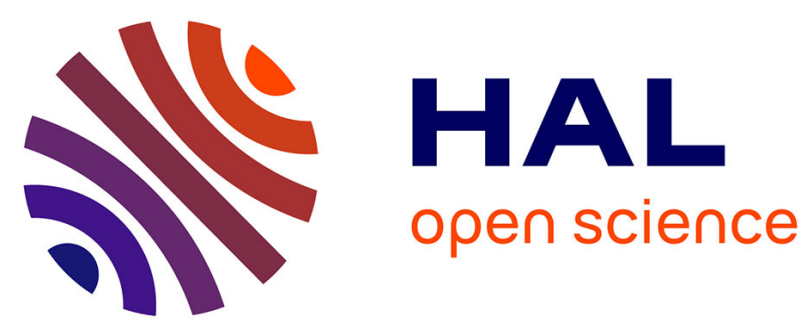

\title{
Calcium pyrophosphate deposition (CPPD) in a liver transplant patient: are hypomagnesemia, tacrolimus or both guilty? A case-based literature review
}

Simon Cadiou, Antonia Le Gruyer, Baptiste Giguet, François Robin, Morgane Milin, Xavier Guennoc, Pascal Guggenbuhl, Marine de Saint-Riquier

\section{To cite this version:}

Simon Cadiou, Antonia Le Gruyer, Baptiste Giguet, François Robin, Morgane Milin, et al.. Calcium pyrophosphate deposition (CPPD) in a liver transplant patient: are hypomagnesemia, tacrolimus or both guilty? A case-based literature review. Rheumatology International, 2022, 42, pp.1105-1112. 10.1007/s00296-021-04828-0 . hal-03194381

\section{HAL Id: hal-03194381 \\ https://hal.science/hal-03194381}

Submitted on 22 Jun 2021

HAL is a multi-disciplinary open access archive for the deposit and dissemination of scientific research documents, whether they are published or not. The documents may come from teaching and research institutions in France or abroad, or from public or private research centers.
L'archive ouverte pluridisciplinaire HAL, est destinée au dépôt et à la diffusion de documents scientifiques de niveau recherche, publiés ou non, émanant des établissements d'enseignement et de recherche français ou étrangers, des laboratoires publics ou privés. 
Calcium Pyrophosphate Deposition (CPPD) in a liver transplant patient: are hypomagnesemia, tacrolimus or both guilty? A case-based literature review.

Cadiou Simon ${ }^{1}$, Le Gruyer Antonia ${ }^{2}$, Giguet Baptiste ${ }^{3}$, Robin François ${ }^{1}$, Milin Morgane ${ }^{4}$, Guennoc Xavier $^{4}$, Guggenbuhl Pascal ${ }^{1,5}$, De Saint-Riquier Marine ${ }^{4}$

${ }^{1}$ Rennes 1 university, Department of Rheumatology, Rennes University Hospital, 35000, Rennes, France. Email: simon.cadiou@ chu-rennes.fr. ORCID ID: 0000-0002-4846-6956

${ }^{2}$ Department of Hepato-gastroenterology, Saint-Brieuc Hospital, 22000, Saint-Brieuc, France.

${ }^{3}$ Rennes 1 university, Department of Hepato-gastro-enterology, Rennes Univsersity Hospital, 35000, Rennes, France.

${ }^{4}$ Department of Rheumatology, Saint-Brieuc Hospital, 22000, Saint-Brieuc, France.

${ }^{5}$ CHU Rennes, Univ Rennes 1, INSERM, Institut NUMECAN (Nutrition Metabolisms and Cancer), F35000, Rennes, France. UMR INSERM U 1241, University of Rennes 1, 35000, Rennes, France. ORCID ID: 0000-0002-8260-1824

\section{Authors contribution list:}

Cadiou Simon, for conception and design, acquisition and interpretation of data and drafting of manuscript.

Le Gruyer Antonia, for case management and revising critically the manuscript.

Giguet Baptiste, for acquisition of data and revising critically the manuscript.

Robin François, for design and drafting of systematic literature review and revising critically the manuscript.

Morgan Milin, for case management and revising critically the manuscript.

Guennoc Xavier, for conception and revising critically the manuscript.

Pascal Guggenbuhl, for conception and design, drafting and revising critically the manuscript.

De Saint Riquier Marine, for case management, conception and design, acquisition of data and revising the manuscript.

All the authors approve this final version and agree to be accountable for all aspects of the work if questions arise related to its accuracy or integrity. 


\begin{abstract}
Introduction: Calcium pyrophosphate deposition (CPPD) can be induced by a persistent hypomagnesemia. Tacrolimus is an immunosuppressive treatment especially used in organ transplant, potentially inducer of hypomagnesemia by renal loss.

Case report: A 53-year-old man, liver transplant 10 months earlier, developed an acute peripheral oligoarthritis of wrist, hip and elbow with fever, associated with acute low back pain. Synovial fluid was sterile, and revealed calcium pyrophosphate crystals. Spinal imaging showed inflammatory changes. Magnesium blood level was low at $0.51 \mathrm{mmol} / \mathrm{l}$, with high fractional excretion in favor of renal loss. Tacrolimus was changed for everolimus, proton pump inhibitor was stopped, and magnesium oral supplementation was started. After 8 months follow-up and slow prednisone tapering, he did not relapse pain.
\end{abstract}

Conclusion: Persistent hypomagnesemia is a rare secondary cause of CPPD. In this entity, drug liability should be investigated such as tacrolimus in organ transplant patient.

Keywords (MeSH): CPPD, Pyrophosphate calcium, magnesium, tacrolimus, liver transplant, spondylodiscitis, vertebral osteomyelitis, crystal

\title{
Highlights:
}

- Hypomagnesemia can be associated to calcium pyrophosphate deposition (CPPD) and CPP crystal arthritis.

- Tacrolimus is largely used in organ-transplantation but might induce hypomagnesemia by renal loss.

- Magnesium level and drug liability should be investigated in patients with CPPD.

\section{Author Contributions Statement}

All authors approved the final manuscript as submitted and agree to be accountable for all aspects of the work.

\section{Disclosure of interest}

None of the authors have conflict of interest to declare for this article.

\section{Consent}

Patient gave consent to participate and for publishing.

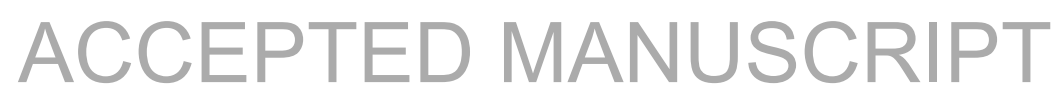




\section{Introduction}

Calcium pyrophosphate deposition (CPPD) disease is a common cause of rheumatological symptoms: from an acute form (CPP crystal arthritis), which is typically revealed by arthritis of specific joints (knee, wrist), to chronic form with polyarticular involvement mimicking other rheumatologic conditions and with osteoarthritis[1]. Axial symptoms of CPPD have been also described, mainly as Crown dens syndrome[2], but also less frequently as acute spinal pain mimicking spondylodiscitis[3]. Unlike gout, CPPD mainly involved cartilage and rarely non cartilaginous tissues[1]. Primary hyperparathyroidism, hemochromatosis or genetic hypophosphatasia are classical causes of CPPD[4], but chronic hypomagnesemia is also recognized as a risk factor, especially in Gitelman's syndrome[5, 6] or digestive loss of short bowel syndrome[7].

CPP crystal arthritis can mimic septic arthritis, with fever and systemic reaction. Synovial fluid (SF) analysis has to be done to rule out septic arthritis and look for calcium pyrophosphate crystals.

Hypomagnesemia can be induced by tacrolimus through a renal loss in the distal part of the nephron[8] and a tacrolimus-induced hypomagnesemia associated to CPPD a is classically reported inter literature $[9,10]$.

In this paper, we report the case of a liver transplant patient under tacrolimus with hypomagnesemia who experienced an acute axial and peripheral CPPD, with pre-existing asymptomatic crystal deposition disease. Patient gave consent for publishing. In a second part, a literature review of CPPD in patients with tacrolimus and others anti-calcineurins have been done.

\section{Case report}

A 53-year-old patient was admitted in the emergency Department at St-Brieuc Hospital (Brittany, France) for acute low back pain. He used to have a mild chronic low back pain, which did not require painkillers. His medical history was a liver cirrhosis from a chronic alcohol abuse, which lead to liver transplantation. Post-transplant follow-up revealed a hepatic artery stenosis, treated with acetylsalicylate $75 \mathrm{mg}$ with co-prescription of pantoprazole $20 \mathrm{mg}$. He never had arthritis or known CPPD in the past. He did not report any medical history of CPPD in his parents, nor kidney disease such as Gitelman's syndrome. Timeline patient was resumed in Figure 1.

At admission, he suffered from an acute low back pain with multidirectional lumbar spine stiffness reduced mobility but without fever. Right hip was also painful in rotational movements.

The patient had a high CRP $(70 \mathrm{mg} / \mathrm{l})$, mild kidney failure (creatinine at $135 \mu \mathrm{mol} / \mathrm{l}$ and clearance CKD-EPI $52 \mathrm{ml} / \mathrm{min} / 1.73 \mathrm{~m}^{2}$ ), elevated WBC at $20.1 \mathrm{G} / \mathrm{L}$ (with $16.26 \mathrm{G} / \mathrm{L}$ of neutrophils) and high alkaline phosphatase at $169 \mathrm{U} / \mathrm{L}$ (range: 35-105 UI/L) with normal gamma-glutamyl transferase and transaminases. Serum uric acid was normal.

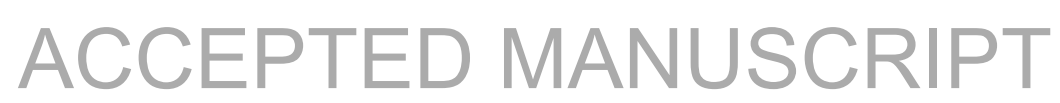


Twenty-four hours later, he developed fever and arthritis of the right wrist. A SF macroscopic analysis showed a purulent liquid. In fear of septic arthritis, a treatment with IV Ceftriaxone (2g/day) was initiated. SF analysis showed 100.000 leucocytes $/ \mathrm{mm}^{3}$ with $90 \%$ of neutrophils. Calcium pyrophosphate (CPP) crystals were also identified, without monosodic urate crystals (MSU).

Right wrist X-rays showed chondrocalcinosis (CC) of the triangular fibrocartilage. At lumbar spine there was a marked discopathy L3-L4, with erosions at the inferior L3 endplate and superior L4 endplate suspect of spondylodiscitis in an immunosuppressed patient. A computed tomography (CT) done at his admission revealed an erosive discopathy of lumbar spine, without discs calcifications and without abscess. In addition, a calcium pyrophosphate deposit in $\mathrm{C} 1-\mathrm{C} 2$ was found on a previous CT done before liver transplant (Figure 2). Magnetic resonance imaging (MRI) of lumbar spine showed inflammatory signal in Short tau inversion recovery (STIR) sequences on several lumbar endplates with hypointense signal in T1 sequence associated with hyperintense signal in T2 sequence, especially of L1 and L2 (Figure 3 A, B and C). A septic spondylodiscitis has been ruled out due to multistage involvement and sterile blood culture, and discovertebral was not realized. As a result, the diagnosis of axial CPPD was made.

Finally, he developed an other arthritis of the left elbow with ultrasound showing joint effusion with a synovial hypertrophy and power doppler signal. A SF analysis showing CPP without MSU. An arthritis of the right hip was identified with ultrasounds with capsular thickening without other anomalies, including no hyperechoic deposition in the labrum or hyalin cartilage. Hip arthrocentesis was not performed due to the diagnosis of CPP crystal oligoarthritis. All synovial fluids and other samples as blood culture were finally negative for bacterial research. Prednisone $20 \mathrm{mg} /$ day was initiated with a quick and remarkably effectiveness on peripheral and axial symptoms. A transient spinal immobilization completed the low back pain treatment.

An etiology to CPPD has been researched. It showed normal calcium and phosphate blood levels; normal parathormone level at $21.2 \mathrm{pg} / \mathrm{ml},(6.5-36.8)$. Ferritin was elevated at $711 \mathrm{ng} / \mathrm{ml}$ (30-400) in an inflammatory condition with normal CST, and genetic research of HFE gene mutation for hemochromatosis was negative for $\mathrm{C} 282 \mathrm{Y}$ and H63D. Serum magnesium was measured at $0.51 \mathrm{mmol} / \mathrm{l}$ (0.66-1.07) with normal kaliemia. It was attributed to a concomitant overdosage of tacrolimus at 12.2 $\mathrm{mg} / \mathrm{l}$ (5-10) due to mild kidney failure, cholestasis and patient mismanagement of immunosuppressive therapy. An oral supplementation with $184 \mathrm{mg}$ of magnesium twice a day was started and patient returned home. Even if CPPD existed prior to transplantation, since the patient was single with no offspring and had only one older asymptomatic sister, no ANKH or OPG mutation testing was undertaken.

Three weeks later, he was admitted again for a recurrent acute low back pain and oligoarthritis (right hip and left knee). A novel SF analysis of the left knee ruled out a septic arthritis. A spinal MRI

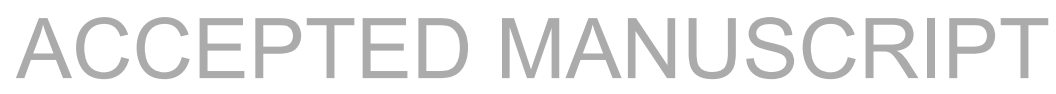


showed persistent spondylodiscitis (Figure 3, D). While his treatments were prepared and delivered by a nurse at home, serum magnesium was still low, at $0.46 \mathrm{mmol} / \mathrm{l}$ and fractional excretion was elevated at $7.0 \%$ ( $<2 \%$ in extrarenal loss), despite oral supplementation and normal tacrolemia. Pantoprazole was then stopped as a potential cause of hypomagnesemia[11]. After negative septic investigations, oral prednisone was restarted with a more progressive gradual decrease. Again, peripheral arthritis quickly disappeared and low back pain decreased of about 70\%. Tacrolimus therapy was switched for everolimus, another anticalcineurin drug which have not been described to induce hypomagnesemia yet.

After 5 months of follow-up, the patient did not have recurrence of CPPD arthritis nor acute back pain. Serum magnesium was still low at $0.56 \mathrm{mmol} / \mathrm{l}$, but with overdosage of everolimus at 21.1 $\mathrm{ng} / \mathrm{ml}$ (3.0-8.0). Oral magnesium supplementation has been continued. He had no relapse after 8 months of follow-up under a $5 \mathrm{mg}$ course of prednisone per day, but serum magnesium remained low despite everolimus switch without overdosage. Oral magnesium supplementation was increased to $184 \mathrm{mg}$ fourth a day. Everolimus can also induce hypomagnesemia as well as tacrolimus, but was continued for immunosuppression and because patient did not relapse CPPD under five mg of prednisone.

\section{Methods}

Based on a PubMed and Web of science search on the $10^{\text {th }}$ of October 2020, we identified CPPD associated to tacrolimus treatments and anti-calcineurin. We used the following keywords: "tacrolimus OR everolimus OR ciclosporin OR anticalcineurin" AND "CPPD OR chondrocalcinosis OR pyrophosphate OR crystal arthritis". Results of the literature review are summarized in Figure 4 according to the PRISMA flow diagram. We have mainly excluded articles about gout. We finally selected articles mentioning patients with CPPD arthritis and tacrolimus or other anticalcineurin treatments.

\section{Review}

Peripheral CPPD have been reported in three articles in patients with anticalcineurin drugs [1214]. Perez-Ruiz et al. [12] described two cases of CPPD in liver transplant patients with tacrolimus. The two patients had chronic $\mathrm{C}$ hepatitis. The first case was a woman of 64 y.o. with acute arthritis of the third metacarpophalangeal joint (MCP) and wrist 13 days after liver transplantation. X-ray showed CC of the triangular ligament. SF was inflammatory and showed calcium pyrophosphate crystals. Blood magnesium was low at $13.6 \mathrm{mg} / \mathrm{l}(\mathrm{N}>17.5 \mathrm{mg} / \mathrm{l})$ with elevated fractional excretion at $8.35 \%$. A short course of colchicine and an oral supplementation of magnesium was started. She did not relapse after 6 months of follow up, and blood magnesium was normal. The second patient, a 48 y.o. woman, developed an acute arthritis of the knee with purulent SF. Cultures were sterile and SF analysis revealed calcium pyrophosphate crystals. However, X-ray did not show CC. Serum magnesium level was low at 1.39 $\mathrm{mg} / \mathrm{dl}$ despite oral supplementation with magnesium salt $300 \mathrm{mg} /$ day at time of transplantation.

\section{ACCEPTED MANUSCRIPT}


Fractional excretion of magnesium was increased at $10.21 \%$. Blood magnesium normalized after increased supplementation, and colchicine was initiated with no relapse after 6 months follow-up.

Recently, Diet et al. [13] focused on musculoskeletal manifestations in liver transplant patients. Three patients on 234 (1.3\%) had CPPD compared to the higher proportion of gout (16/234, 6.8\%). Two hospitalized patients had SF showing calcium pyrophosphate, and one outpatient had CPPD on X-Ray. Only one of the three had hypomagnesemia at time of crystal-arthritis.

Cenin et al.[14] described 15 crystal-induced-arthritis among 450 patients (3.3\%) underwent allogeneic hematopoietic cell transplant. All patients received tacrolimus with high concentration (median level of $11.4 \mathrm{mg} / \mathrm{l}$, range from 7.3 to $19.7 \mathrm{mg} / \mathrm{l})$. All patients had low magnesemia $(<18 \mathrm{mg} / \mathrm{l}$ ) at time of arthritis. Five patients had a known osteoarthritis of the same joint, and two patients had hemochromatosis. All crystal-arthritis were presumed to be CPPD and no patients had hyperuricemia. However, only five patients had a definite or probable CPPD with SF showing calcium pyrophosphate or CC on X-ray. The ten others had only probable CPPD without SF analysis available nor X-ray proof of CC.

No case of axial CPPD associated to hypomagnesemia nor tacrolimus and anti-calcineurin in organ-transplant patients have been described yet.

\section{Discussion}

CPPD is well known to be associated with persistent hypomagnesemia[4]. It is not clear if hypomagnesemia triggered CPPD arthritis or is an independent risk factor. Gitelman's syndrome which is a genetic disease argue in favor of an independent cause of calcium pyrophosphate deposition[5]. Case report of persistent hypomagnesemia associated to short bowel syndrome[7] suggest that acquired persistent hypomagnesemia can lead to CPPD. Hypomagnesaemia may decreased CPP solubility and then CPP deposit[1]. Magnesium may also trigger CPPD flares throw complex pathogenesis.

First of all, magnesium is directly involved in inorganic pyrophosphate (PPi) production in extracellular matrix. Magnesium facilitates pyrophosphate catabolism acting as a pyrophosphatase cofactor which catalyse Adenosine triphosphate (ATP) in adenosine diphosphate (ADP) + PPi [1]. A low magnesium level promotes then the accumulation of calcium pyrophosphate. On the other hand, NLRP3 inflammasome activation in CPPD disease have been proven[15]. Even if mechanisms and signals leading NLRP3 inflammasome are not fully understood, a second activation of caspase-1 inflammasome for interleukine-1 $\beta$ production driven by ATP [16] may have a role in CPPD flares. One can hypothesize that an acute extracellular excess of ATP induced by a decreased pyrophosphatase activity in a hypomagnesemia patient may lead to inflammasome activation and therefore to clinical flare of a CPPD.

However, magnesium distribution in the body may be difficult to evaluate. About $99 \%$ of the magnesium is extra-vascular, and about half is in bones for hydroxyapatite mineralization[17].

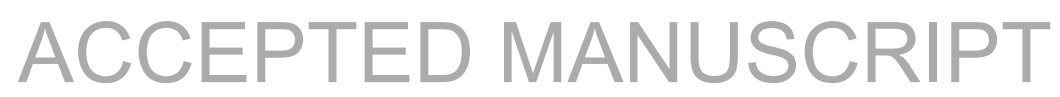


Therefore, magnesium concentration in blood may not totally reflect magnesium concentration in soft tissue such as cartilage, and thus calcium pyrophosphate crystallization. Ionized magnesium level may be useful in case of suspected hypomagnesemia with normal serum magnesium level[17].

There are many drugs acting on the regulation of magnesium efflux and influx such as tacrolimus and cetuximab. Furthermore, standard medications such as loop and thiazide diuretics can induce magnesium renal loss and hypomagnesemia [17]. Increased renal loss and decreased gastrointestinal absorption are also described with proton pump inhibitors[11, 18]. Such treatment involved in serum magnesium imbalance must be taken into account in case of CPPD flares, especially when recurrent. In case of recurrent arthritis, a change in therapeutic class may be proposed or the indication of this therapy should be re-evaluated. In previous cases, tacrolimus was continued and serum magnesium normalized with oral supplementation.

Curiously, no cases of CPP crystal arthritis in-patient with tacrolimus after kidney transplant have been described yet. However, kidney transplantation is the most common organ transplant. It may be explained by hypocalcemia in patients with chronic kidney failure. Just as hypercalcemia is associated with CPPD in primary hyperparathyroidism[1], we hypothesize that hypocalcemia may be a protective factor to develop CPPD.

In the same way, the role of proton pump inhibitors in CPPD remains a point of interest. Proton pump inhibitors are known to provide chronic hypocalcemia and chronic hypomagnesemia through hypochlorhydria[19]. On one hand, some authors suggest a protective role in developing CPPD[20] which may be consistent with chronic induced hypocalcemia, but not with induced hypomagnesemia. On the other hand, proton pump inhibitors are associated to recurrence of acute CPP crystal arthritis which may be consistent with hypomagnesemia but not hypocalcemia. The role of proton pump inhibitors in developing or triggering CPPD disease or flare is not clear, and more studies are necessary.

In previous articles studied in this review, almost every patient was treated with colchicine for flares or to prevent recurrence of arthritis. Colchicine and tacrolimus is not a harmless association: metabolism with CYP3A4 for both drugs may increase its concentrations[21]. Yousuf Bah et al. reported a case of toxic myopathy in a kidney transplant patient with moderate chronic kidney failure [22]. Moreover, elevated blood concentration of anticalcineurins is associated to kidney failure [23, 24] and thus can lead to overdosage and toxicity of colchicine. Considered with the low level of evidence of colchicine effectiveness in acute and chronic CPPD[25, 26], colchicine should be used with caution in solid organ transplant patients receiving tacrolimus and anti-calcineurin drugs. In our case, we preferred glucocorticoids instead of colchicine to treat the oligoarthritis with axial CPPD.

Tacrolimus itself can induce musculoskeletal symptoms. The calcineurin-inhibitor induced pain syndrome (CIPS) have been first described by Grotz et al. [27] in lower-limb extremities. CIPS is described in 0.8 to $5.8 \%$ of patient under tacrolimus for kidney transplant but may have been described

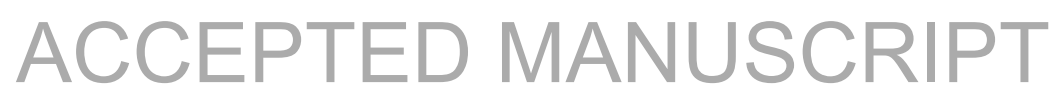


much earlier in patient with polyarticular symptoms without alternative diagnosis in heart transplant patients[28]. MRI with patchy bone marrow oedema and bone scintigraphy may be helpful for diagnosis [29]. Vasoconstriction due to anticalcineurin may be involved in symptoms [27]. Overdosage of tacrolimus may occurred and a pain relief when stopping anticalcineurin is a good diagnosis criterion. The CIPS have a distinct presentation compared to our case: it is not revealed by inflammatory pains or arthritis but as mechanical pain of limbs, and spine is rarely involved [29].

To our knowledge, we described the first case of axial CPPD flare associated with a tacrolimusinduced hypomagnesemia. In our case report, even if CT did not show typical disc calcifications of lumbar spine, some elements are in favor of an axial CPPD: a pre-existing crown dens imaging, erosive changes of vertebral endplates on CT with bone edema on MRI and gadolinium enhancement, absence of abscess or epiduritis, negativity of the totality of bacteriological samples and a concomitant axial and peripheral symptoms as well as their rapid improvement under corticosteroid therapy. Finally, the link between degenerative disc disease and CPPD is questionable: some studies showed CPP on degenerative scoliotic disk without known CPPD disease[30]. This would suggest that degenerative disc diseases associated with "asymptomatic" CPPD may be a counterpart to osteoarthritis in chronic peripheral CPPD.

\section{Conclusion}

Axial and peripheral CPPD flare in a liver transplant patient may mimic a septic presentation which have to be ruled out. Magnesium level should be investigated, especially if drugs acting on its regulation are present. Tacrolimus is one of them, such as proton pump inhibitor. An oral supplementation of magnesium and treatment adjustments - if possible - should be considered. 
1. Rosenthal AK, Ryan LM (2016) Calcium Pyrophosphate Deposition Disease. N Engl J Med 374:2575-2584. https://doi.org/10.1056/NEJMra1511117

2. Moshrif A, Laredo JD, Bassiouni H, et al (2019) Spinal involvement with calcium pyrophosphate deposition disease in an academic rheumatology center: A series of 37 patients. Semin Arthritis Rheum 48:1113-1126. https://doi.org/10.1016/j.semarthrit.2018.10.009

3. Grobost V, Vayssade M, Roche A, et al (2014) Axial calcium pyrophosphate dihydrate deposition disease revealed by recurrent sterile spondylodiscitis and epidural abscess. Joint Bone Spine 81:180-182. https://doi.org/10.1016/j.jbspin.2013.07.007

4. Jones AC, Chuck AJ, Arie EA, et al (1992) Diseases associated with calcium pyrophosphate deposition disease. Semin Arthritis Rheum 22:188-202. https://doi.org/10.1016/00490172(92)90019-a

5. Ea H-K, Blanchard A, Dougados M, Roux C (2005) Chondrocalcinosis secondary to hypomagnesemia in Gitelman's syndrome. J Rheumatol 32:1840-1842

6. Cipolletta E, Di Matteo A, Filippucci E, Grassi W (2019) Calcium Pyrophosphate Deposition Disease in a Patient with Familial Hypokalemia-Hypomagnesemia (Gitelman's-Syndrome): A Case Report. Ultraschall Med. https://doi.org/10.1055/a-0990-9960

7. Richette P, Ayoub G, Bardin T, et al (2005) Hypomagnesemia and chondrocalcinosis in short bowel syndrome. J Rheumatol 32:2434-2436

8. Nijenhuis T, Hoenderop JGJ, Bindels RJM (2004) Downregulation of $\mathrm{Ca}(2+)$ and $\mathrm{Mg}(2+)$ transport proteins in the kidney explains tacrolimus (FK506)-induced hypercalciuria and hypomagnesemia. J Am Soc Nephrol 15:549-557. https://doi.org/10.1097/01.asn.0000113318.56023.b6

9. Favero M, Calò LA, Schiavon F, Punzi L (2011) Miscellaneous non-inflammatory musculoskeletal conditions. Bartter's and Gitelman's diseases. Best Practice \& Research Clinical Rheumatology 25:637-648. https://doi.org/10.1016/j.berh.2011.10.013

10. Guerne P-A (2010) [Chondrocalcinosis and calcium pyrophosphate (CPP) crystal deposition disease in 2010]. Revue Medicale Suisse 6:555-556, 558, 560-561

11. Cheungpasitporn W, Thongprayoon C, Kittanamongkolchai W, et al (2015) Proton pump inhibitors linked to hypomagnesemia: a systematic review and meta-analysis of observational studies. Ren Fail 37:1237-1241. https://doi.org/10.3109/0886022X.2015.1057800

12. Perez-Ruiz F, Testillano M, Gastaca MA, Herrero-Beites AM (2001) "Pseudoseptic" pseudogout associated with hypomagnesemia in liver transplant patients. Transplantation 71:696-698. https://doi.org/10.1097/00007890-200103150-00022

13. Diep JT, Kerr LD, Barton C, Emre S (2008) Musculoskeletal manifestations in liver transplantation recipients. Journal of Clinical Rheumatology: Practical Reports on Rheumatic \& Musculoskeletal Diseases 14:257-260. https://doi.org/10.1097/RHU.0b013e3181870212

14. Cenin DA, Freyer CW, Ligon CB, et al (2020) Tacrolimus induced pseudogout following allogeneic hematopoietic cell transplant. J Oncol Pharm Pract 1078155220951241. https://doi.org/10.1177/1078155220951241

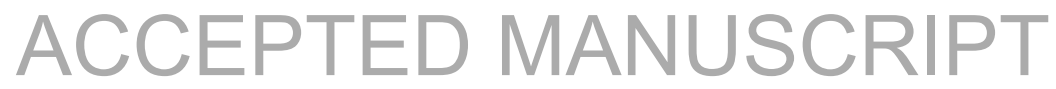


15. Martinon F, Pétrilli V, Mayor A, et al (2006) Gout-associated uric acid crystals activate the NALP3 inflammasome. Nature 440:237-241. https://doi.org/10.1038/nature04516

16. Mariathasan S, Newton K, Monack DM, et al (2004) Differential activation of the inflammasome by caspase-1 adaptors ASC and Ipaf. Nature 430:213-218. https://doi.org/10.1038/nature02664

17. Jahnen-Dechent W, Ketteler M (2012) Magnesium basics. Clin Kidney J 5:i3-i14. https://doi.org/10.1093/ndtplus/sfr163

18. Srinutta T, Chewcharat A, Takkavatakarn K, et al (2019) Proton pump inhibitors and hypomagnesemia: A meta-analysis of observational studies. Medicine (Baltimore) 98:e17788. https://doi.org/10.1097/MD.0000000000017788

19. Sivakumar J (2016) Proton pump inhibitor-induced hypomagnesaemia and hypocalcaemia: case review. Int J Physiol Pathophysiol Pharmacol 8:169-174

20. Kleiber Balderrama C, Rosenthal AK, Lans D, et al (2017) Calcium Pyrophosphate Deposition Disease and Associated Medical Comorbidities: A National Cross-Sectional Study of US Veterans. Arthritis Care Res (Hoboken) 69:1400-1406. https://doi.org/10.1002/acr.23160

21. Amanova A, Kendi Celebi Z, Bakar F, et al (2014) Colchicine levels in chronic kidney diseases and kidney transplant recipients using tacrolimus. Clin Transplant 28:1177-1183. https://doi.org/10.1111/ctr.12448

22. Yousuf Bhat Z, Reddy S, Pillai U, et al (2016) Colchicine-Induced Myopathy in a TacrolimusTreated Renal Transplant Recipient: Case Report and Literature Review. Am J Ther 23:e614616. https://doi.org/10.1097/MJT.0000000000000044

23. Nguyen LS, Vautier M, Allenbach Y, et al (2019) Sirolimus and mTOR Inhibitors: A Review of Side Effects and Specific Management in Solid Organ Transplantation. Drug Saf 42:813-825. https://doi.org/10.1007/s40264-019-00810-9

24. Kolaitis NA, Calabrese DR, Ahearn P, et al (2019) Tacrolimus trough monitoring guided by mass spectrometry without accounting for assay differences is associated with acute kidney injury in lung transplant recipients. Am J Health Syst Pharm 76:2019-2027. https://doi.org/10.1093/ajhp/zxz243

25. Zhang W, Doherty M, Pascual E, et al (2011) EULAR recommendations for calcium pyrophosphate deposition. Part II: management. Ann Rheum Dis 70:571-575. https://doi.org/10.1136/ard.2010.139360

26. Alvarellos A, Spilberg I (1986) Colchicine prophylaxis in pseudogout. J Rheumatol 13:804-805

27. Grotz WH, Breitenfeldt MK, Braune SW, et al (2001) Calcineurin-inhibitor induced pain syndrome (CIPS): a severe disabling complication after organ transplantation. Transpl Int 14:1623. https://doi.org/10.1007/s001470000285

28. Rozenberg S, Bourgeois P (1995) [Osteo-articular complications of heart transplantation]. Presse Med 24:1809-1812

29. Udomkarnjananun S, Townamchai N, Virojanawat M, et al (2018) An Unusual Manifestation of Calcineurin Inhibitor-Induced Pain Syndrome in Kidney Transplantation: A Case Report and Literature Review. Am J Case Rep 19:442-446. https://doi.org/10.12659/ajcr.908886

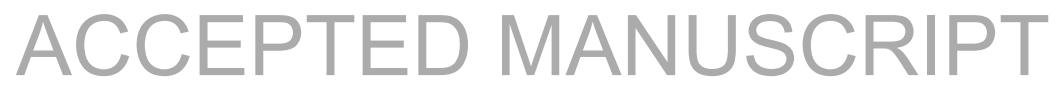


30. Lee RS, Kayser MV, Ali SY (2006) Calcium phosphate microcrystal deposition in the human intervertebral disc. J Anat 208:13-19. https://doi.org/10.1111/j.1469-7580.2006.00504.x 
Figure 1. CPPD patient's timeline.

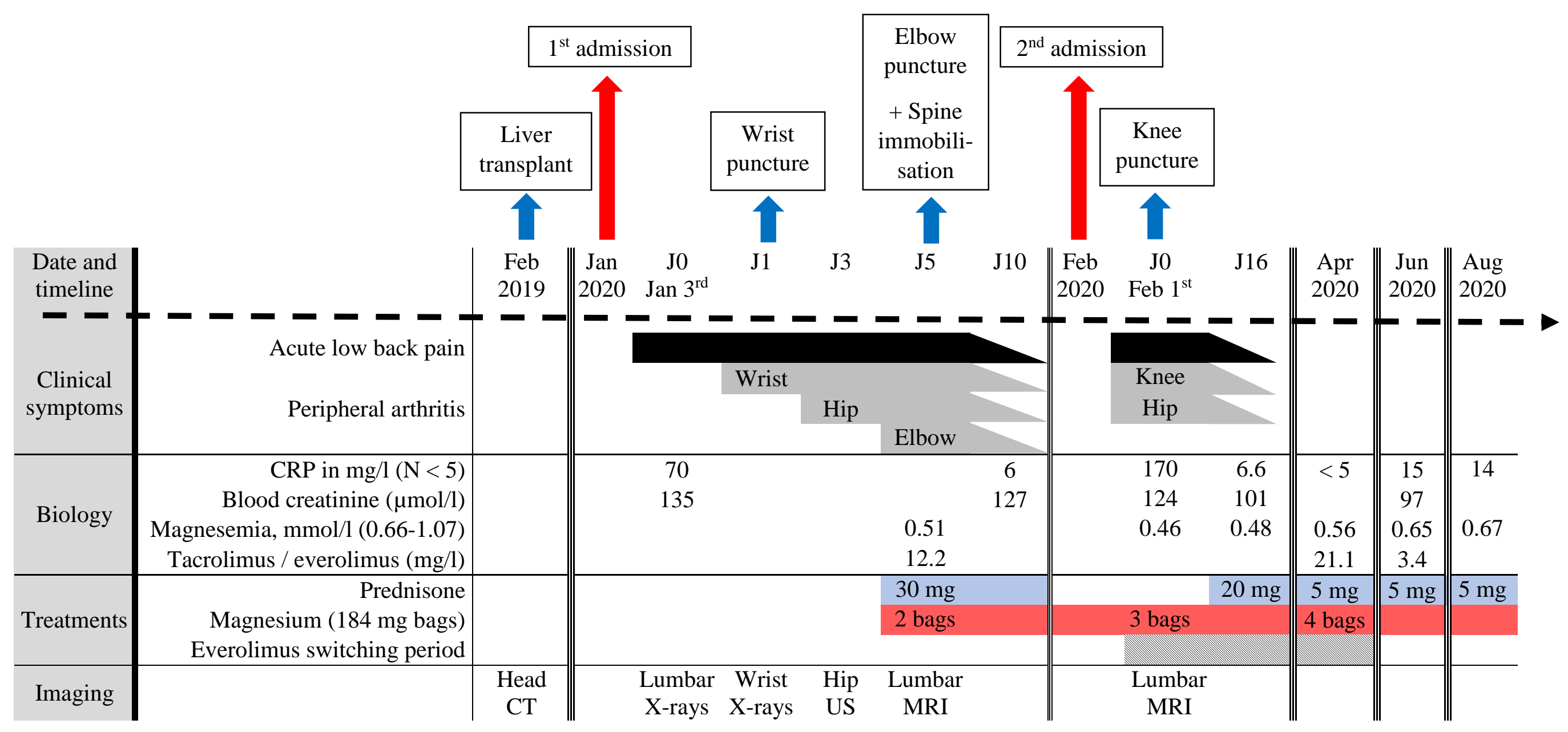


Figure 2. (Left) sagittal lumbar spine on Computed Tomography showing erosive changes of L3, L4 and L5 endplates (arrow heads) with disc degeneration without discal calcification. (Right) crown dens syndrome (dashed arrow) in axial view one year before liver transplant.

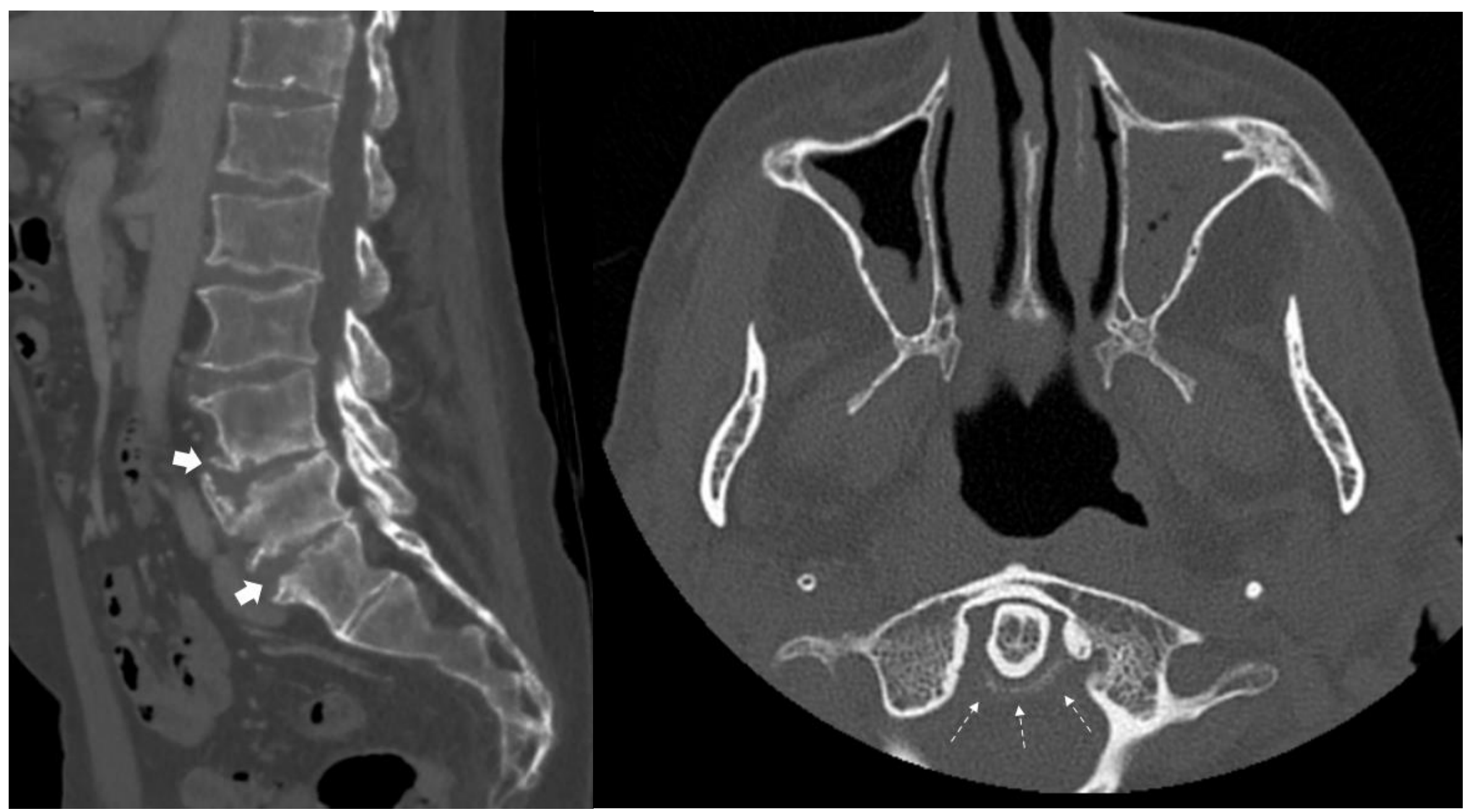


Figure 3. MRI of lumbar spine at diagnosis: (A) T1 sequence, (B) T2 sequence and (C) STIR sequence, showing inflammatory changes of L2 to L5 vertebral endplates (example with inferior endplates of L5, white arrows: hyposignal in T1, hypersignal in T2 et STIR sequences). (D) MRI of the lumbar spine three months later on T1 sequence, showing Gadolinium enhancement (star) of several discs and endplates
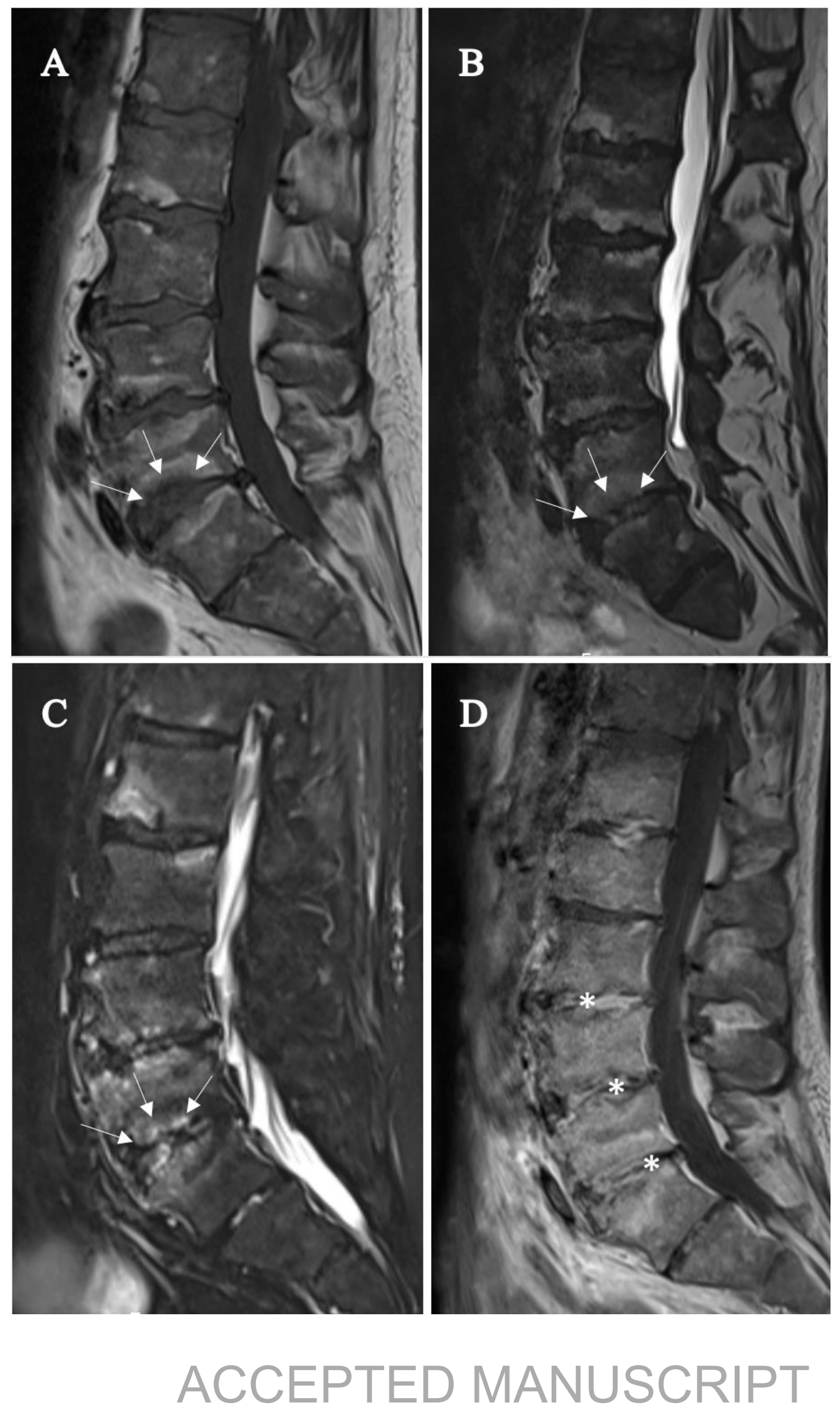
Figure 4. PRISMA ${ }^{\circledR}$ flow diagram of the literature review

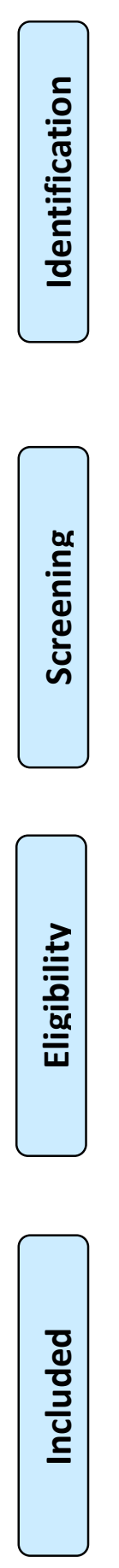

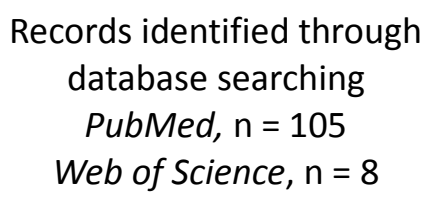
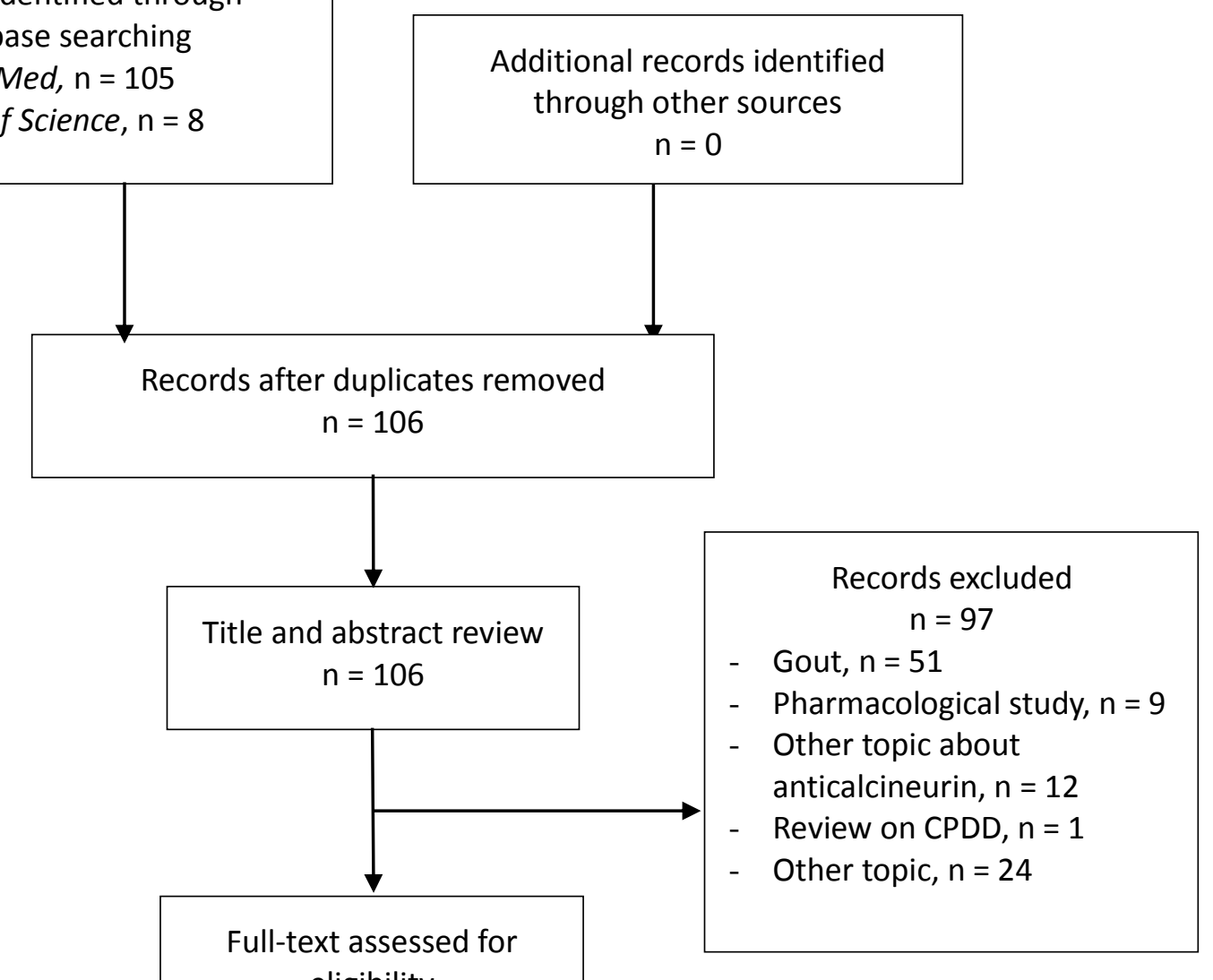
eligibility

$\mathrm{n}=9$

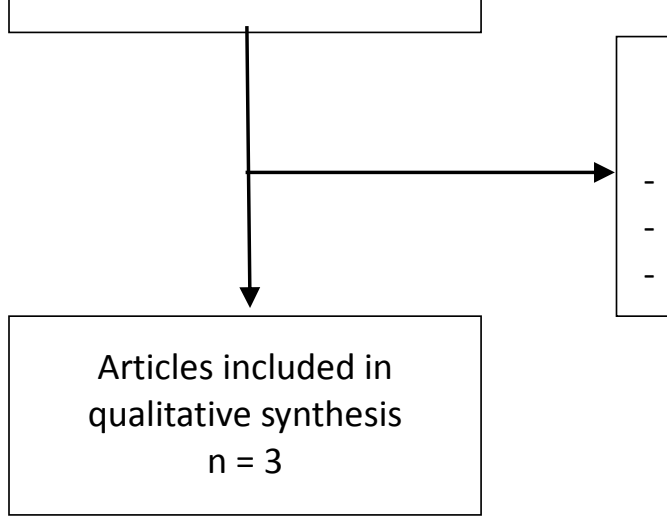

Full-text articles excluded

$$
\begin{aligned}
& n=6 \\
\text { Gout, } & n=2
\end{aligned}
$$$$
\text { - } \quad \text { No CPDD cases, } n=2
$$

- Review on CPDD, $n=2$

PRISMA $^{\oplus} 2009$ Flow Chart. Flow chart design was described by Moher D. and al. 